\title{
Impact of Maintenance Steroids versus Rapid Steroid Withdrawal in African-American Kidney Transplant Recipients: Comparison of Two Urban Centers
}

\author{
W. James Chon ${ }^{*}$, Amishi Desai ${ }^{*}$, Coady Wing33, Divya Arwindekar ${ }^{4}$, Ignatius Y. S. Tang ${ }^{4,5}$, \\ Michelle A. Josephson', Sanjeev Akkina ${ }^{2}$ \\ ${ }^{1}$ Department of Medicine, Division of Nephrology, University of Chicago Medicine, Chicago, IL, USA \\ ${ }^{2}$ Department of Medicine, Division of Nephrology, Loyola University Medical Center, Maywood, IL, USA \\ ${ }^{3}$ School of Public and Environmental Affairs, Indiana University, Bloomington, IN, USA \\ ${ }^{4}$ Department of Medicine, Division of Nephrology, University of Illinois Hospital \& Health Sciences System, \\ Chicago, IL, USA \\ ${ }^{5}$ Department of Medicine, Division of Nephrology, Jesse Brown VA Medical Center, Chicago, IL, USA \\ Email: Sanjeev.akkina@lumc.edu
}

Received 14 February 2016; accepted 14 March 2016; published 17 March 2016

Copyright (C) 2016 by authors and Scientific Research Publishing Inc.

This work is licensed under the Creative Commons Attribution International License (CC BY).

http://creativecommons.org/licenses/by/4.0/

(c) (i) Open Access

\section{Abstract}

Background: Rapid steroid withdrawal (RSW) is used increasingly in kidney transplantation but long-term outcomes in African-American (AA) recipients are not well known. We compared 1 and 5 year transplant outcomes in a large cohort of AA patients who were maintained on continued steroid therapy (CST) to those who underwent RSW. Methods: Post-transplant courses of A as receiving kidney allografts from 2003-2011 at two urban transplant centers in Chicago were followed. Prior to outcome analysis, we used Inverse Probability of Treatment Weights (IPTW) to match the two groups on a set of baseline risk factors. Graft and patient survival, GFR at 1 and 5 years, incidence and type of rejection, incidence of post-transplant diabetes mellitus (PTDM), delayed graft function, CMV and BK viremia were compared. Results: There were 150 AA recipients in the CST analytic group and 157 in the RSW analytic group. Graft and patient survival was similar between the two groups. Rates of CMV viremia were higher in the RSW compared to the CST analytic group at 1 year. Biopsy-proven acute rejection and PTDM were similar between the RSW and CST groups. Conclusions: In AA recipients, RSW has similar long-term outcomes to CST.

*Both authors contributed equally to this research work.

How to cite this paper: Chon, W.J., et al. (2016) Impact of Maintenance Steroids versus Rapid Steroid Withdrawal in African-American Kidney Transplant Recipients: Comparison of Two Urban Centers. International Journal of Clinical Medicine, 7, 204-216. http://dx.doi.org/10.4236/ijcm.2016.73021 


\section{Keywords}

\section{Kidney Transplant, African-Americans, Steroid Maintenance}

\section{Introduction}

With the availability of more potent immunosuppressive medications, a number of studies have been published over the last two decades evaluating the role of steroid withdrawal in kidney transplantation. The general consensus is that rapid steroid withdrawal (RSW) when compared to continued steroid therapy (CST) is safe and effective and many centers are moving toward a RSW protocol [1]-[16]. However, the safety and efficacy of RSW remain less well-defined in African American (AA) renal transplant recipients. Studies assessing the efficacy of RSW protocols in AA renal transplant recipients were small, short-term, or not randomized between RSW and CST protocols in AA recipients. Furthermore, studies to date include very few, if any, patients for expanded-criteria donors (ECD), donor after circulatory death (DCD), or recipients with elevated panel reactive antibodies (PRA) at the time of transplantation [17]-[24].

We present data comparing RSW AA recipients to CST AA recipients from two urban centers in Chicago. In the CST group, corticosteroids were tapered to maintenance $5 \mathrm{mg}$ daily dosing by 30 days post-transplantation. In the RSW group, steroids were withdrawn within 5 days post-transplantation. To our knowledge this is the only comparison study between RSW and CST in AA recipients. Further, it represents the largest cohort of AAs and the longest outcome data to date in this population.

\section{Materials and Methods}

\subsection{Study Population}

We retrospectively reviewed data from AA transplant recipients at two Chicago-area academic medical centers from 2003 to 2011. During this period, The University of Chicago followed a continued steroid therapy (CST) protocol, and the University of Illinois employed a rapid steroid withdrawal protocol (RSW). Practice patterns at each center post-transplant are summarized in Table 1. Inclusion criteria for the study were AA transplant recipients at least 18 years of age who received either a deceased donor (including ECD and DCD) or living donor kidney, and were induced with anti-thymocyte globulin. Exclusion criteria included: 1) patients requiring corticosteroids prior to transplantation that were continued after transplant; 2) re-transplants or multi-organ transplants; and 3) positive cross-match and $\mathrm{ABO}$ incompatible transplants that required maintenance steroid therapy. The Institutional Review Board at both the University of Chicago and University of Illinois at Chicago approved this study.

\subsection{Outcomes}

Primary end-points included patient, graft, and death-censored graft survival. Secondary end-points included the estimated glomerular filtration rate (eGFR) at 1 and 5 years as determined by the Modification of Diet in Renal Diseases (MDRD) equation, the 1 and 5 year incidence of acute cellular and humoral rejection, and cumulative incidence of post-transplant diabetes mellitus (PTDM) defined as the a fasting glucose $>126 \mathrm{mg} / \mathrm{dL}$ or random glucose $>200 \mathrm{mg} / \mathrm{dL}$ requiring the initiation of oral anti-hyperglycemic or insulin based agents after transplant.

\subsection{Immunosuppression Treatment Protocol}

Patients in the CST group were induced with 4 doses of anti-thymocyte globulin (maximum dose $100 \mathrm{mg} / \mathrm{day}$ ). Either mycophenolate mofetil $1000 \mathrm{mg}$ twice a day or mycophenolate sodium $720 \mathrm{mg}$ twice was used as an anti-proliferative agent. Corticosteroid treatment included intravenous methylprednisolone followed by a taper to maintenance steroid dosing of $5 \mathrm{mg}$ per day at 1 month post-transplant. Patients were maintained on tacrolimus with target 12-hr trough level ranging 6 - $9 \mathrm{ng} / \mathrm{ml}$ for the first six months and then 4 - $7 \mathrm{ng} / \mathrm{ml}$ thereafter (Table $1)$.

In the RSW group, patients were induced with 5 doses of $1.5 \mathrm{mg} / \mathrm{kg} /$ day anti-thymocyte globulin based on ideal body weight. Mycophenolate mofetil $1000 \mathrm{mg}$ twice a day or mycophenolate sodium $720 \mathrm{mg}$ twice a day 
Table 1. Practice differences between the CST and RSW centers.

\begin{tabular}{|c|c|c|}
\hline & CST & RSW \\
\hline Induction Therapy & $\begin{array}{l}\text { Anti-thymocyte globulin } 1.5 \mathrm{mg} / \mathrm{kg} \times 4 \text { doses (maximum } 100 \mathrm{mg} / \\
\text { day) } \\
\text { Methylprednisolone }\end{array}$ & $\begin{array}{l}\text { Anti-thymocyte globulin } 1.5 \mathrm{mg} / \mathrm{kg} \text { (ideal } \\
\text { body weight) } \times 5 \text { doses (no maximum dose) } \\
\text { Methylprednisolone }\end{array}$ \\
\hline $\begin{array}{l}\text { Maintenance } \\
\text { immunosuppression }\end{array}$ & $\begin{array}{l}\text { Tacrolimus (trough level) } \\
\bullet \quad 0 \text { - } 6 \text { months }-6-9 \mathrm{ng} / \mathrm{mL} \\
\bullet \quad>6 \text { months }-4-7 \mathrm{ng} / \mathrm{mL} \\
\text { Mycophenolate mofetil } 1000 \mathrm{mg} \text { bid or mycophenolate sodium } \\
720 \mathrm{mg} \text { bid } \\
\text { Prednisone taper to } 5 \mathrm{mg} \text { daily by } 1 \text { month }\end{array}$ & $\begin{array}{l}\text { Tacrolimus (trough level) } \\
\text { - } \quad 0 \text { - } 2 \text { months }-8-12 \mathrm{ng} / \mathrm{mL} \\
\text { - } \quad>2 \text { months }-5-10 \mathrm{ng} / \mathrm{mL} \\
\text { Mycophenolate mofetil } 1000 \mathrm{mg} \text { bid or } \\
\text { mycophenolate sodium } 720 \mathrm{mg} \text { bid } \\
\text { Prednisone tapered off by day } 6\end{array}$ \\
\hline & $\begin{array}{l}\text { CMV } \\
-\quad \text { Valganciclovir for } 3 \text { months } \\
-\quad \text { Acyclovir } \times 1 \text { month for low-risk }\end{array}$ & $\begin{array}{l}\text { CMV } \\
\text { - } \quad \text { Valganciclovir for } 6 \text { months } \\
\text { Pneumpclovir } \times 1 \text { month for low-risk }\end{array}$ \\
\hline Prophylaxis & $\begin{array}{l}\text { - } \quad \text { TMP/SMX single strength daily x } 6 \text { months } \\
\text { - TMP/SMX single strength three times weekly indefinitely } \\
\text { Fungal } \\
\text { - } \quad \text { Oral Fluconazole } \times 1 \text { month }\end{array}$ & $\begin{array}{l}\text { TMP/SMX single strength daily } \times 12 \\
\text { months } \\
\text { Fungal } \\
\text { - Oral nystatin } \times 5 \text { days }\end{array}$ \\
\hline $\begin{array}{l}\text { Diagnosis and } \\
\text { Management of } \\
\text { Rejection }\end{array}$ & $\begin{array}{l}\text { Biopsy-proven only } \\
\text { Banff } 1 \mathrm{~A} / 1 \mathrm{~B} \\
\text { - } \quad \text { Methylprednisolone } 500 \mathrm{mg} \text { daily } \times 3 \text { days } \\
\text { - } \quad \text { Oral taper afterwards } \\
\text { Banff } 2 \mathrm{~A} / 2 \mathrm{~B} / 3 \\
\text { - } \quad \text { Anti-thymocyte globulin }\end{array}$ & $\begin{array}{l}\text { Empiric or biopsy-proven } \\
\text { Banff } 1 \mathrm{~A} / 1 \mathrm{~B} / \text { Empiric } \\
\text { - Methylprednisolone } 500 \mathrm{mg} \text { daily } \times 3 \\
\text { days } \\
\text { Banff } 2 \mathrm{~A} / 2 \mathrm{~B} / 3 \\
\text { - Anti-thymocyte globulin }\end{array}$ \\
\hline
\end{tabular}

was also used as an anti-proliferative agent, and prednisone was tapered quickly from $1 \mathrm{mg} / \mathrm{kg} / \mathrm{day}$ to $0.25 \mathrm{mg} /$ $\mathrm{kg} /$ day and off by post-operative day 6 . Patients were maintained on tacrolimus with target trough of 8 - 12 $\mathrm{ng} / \mathrm{mL}$ in the first 2 months, followed 5 - $10 \mathrm{ng} / \mathrm{mL}$ thereafter.

\subsection{Infection Prophylaxis}

The CST group received valganciclovir cytomegalovirus (CMV) prophylaxis for 3 months in the intermediate risk (donor CMV positive/negative and recipient CMV positive) and high risk group (donor CMV positive and recipient CMV negative). All recipients also received trimethoprim/sulfamethoxazole single-strength daily for Pneumocystis prophylaxis in the first 6 months and then three times weekly indefinitely post-transplantation. Fluconazole fungal prophylaxis was provided for 1 month immediately post-transplantation.

The recipients in the RSW group that were at intermediate or high risk for CMV infection received valganciclovir for 6 months and all recipients received trimethoprim/sulfamethoxazole single-strength daily for the first 12 months post-transplant. No fungal prophylaxis is provided after discontinuation of steroids. For both the CST and RSW groups, acyclovir HSV prophylaxis was used for 1 month if recipients were low risk for CMV (donor and recipient CMV negative).

\subsection{Diagnosis and Management of Rejection}

The incidence of rejection was determined by either biopsy-proven rejection or empiric treatment for rejection as described below. The types of rejection were determined using the Banff '05 criteria when possible. In cases where C4d staining was not done, the Banff '97 criteria were used. Cases that had both an acute cellular component and antibody-mediated component were categorized as antibody-mediated rejection.

The diagnosis and management of rejection varied slightly between the two groups. In the CST group, all clinically suspected rejections had an ultrasound-guided renal allograft biopsy performed. For Banff $1 \mathrm{~A}$ or $1 \mathrm{~B}$ acute cellular rejection (ACR), patients were treated with methylprednisolone $500 \mathrm{mg}$ daily for 3 days followed by a quick taper. Banff 2A or greater ACR were treated with anti-thymocyte globulin. For the RSW group, treatment for clinically suspected rejection without biopsy or a borderline/Banff 1A or 1B ACR included methylprednisolone $500 \mathrm{mg}$ daily for 3 days without an oral taper. Patients with Banff 2A or greater ACR were treated with anti-thymocyte globulin, dosed according to ideal body weight. As per protocol, subjects with first time rejections in the RSW group were not started on oral steroid therapy. 


\subsection{Statistical Analysis}

To assess the baseline differences in patients from the two centers, we examined the difference in means and standardized difference in means (Cohen's D statistic) for a set of demographic and clinical characteristics determined prior to the transplant. The two samples were out of balance with respect several important risk factors. To reduce bias from these baseline differences, we estimated propensity scores using a logistic regression of treatment group membership (RSW/CST) on a list of donor, recipient, and transplant factors including recipient age, gender, body mass index, history of diabetes, pre-transplant dialysis, time on dialysis, primary renal disease, PRA $\geq 30 \%$, Hepatitis C; donor age, gender, race, body mass index (BMI), type; HLA matches, CMV risk, and transplant era. Next, we used inverse probability of treatment weights (IPTW) to assign a weight to each member of the CST group (control). To avoid instability from very large weights, the weights in the CST group were normalized and individuals were trimmed from the sample if their weight represented more than $5 \%$ of the sum of the weights. To maintain symmetry, we also excluded individuals in the RSW group (treatment) if they had propensity scores greater than the minimum propensity score among the individuals who were trimmed from the control group. We examined several candidate specifications for the propensity score model and selected the specification that achieved the most balanced sample. Categorical and continuous outcomes were estimated using IPTW for proportions and means, respectively, and with 95\% confidence intervals.

We used Kaplan-Meier analysis with IPTW to compare graft and patient survival between the two groups. A Cox proportional hazards model using IPTW (unadjusted model) was used to estimate the effect of the maintenance regimen on survival with adjustments for recipient (model 1), donor, and transplant covariates (model 2). The addition of covariates into the Cox proportional model with IPTW provides a doubly robust estimation that increases the chances of an accurate estimation of the outcome [25].

\section{Results}

\subsection{Patient Characteristics}

From 2003 to 2011, 194 patients from the CST group and 212 from the RSW group were initially included in the study. Table 2 shows that, prior to IPTW and trimming, the CST group had more deceased donors, especially DCD, more time on dialysis, fewer black donors, and higher proportion of individuals with a PRA > 30\%. After applying IPTW and trimming, there were 150 individuals in the analytic CST group and 157 in the analytic RSW group.

Prior to outcome analysis, a basic question is whether the analytic sample is sufficiently balanced for sound causal inference. There is no universal standard to apply, of course. However, from a clinical perspective, the analytic sample appears well balanced with respect to key risk factors. In addition, the standardized mean difference in covariates (Cohen's D) is well below 0.25 standard deviations for each of the baseline covariates so that the remaining imbalances is not "too large" from the perspective of one common rule of thumb in the statistical matching literature [26] [27]. In fact, after IPTW and trimming, most baseline covariates have Cohen's D statistics less than 0.10 standard deviations and the most imbalanced variable has a Cohen's D of 0.16 standard deviations.

\subsection{Survival}

Graft, death-censored graft, and patient survival were assessed at 1, 3, and 5 years after transplant. In the CST analytic group, there were 25 graft failures and 24 deaths during the follow up period while the RSW analytic group had 24 graft failures and 18 deaths (Table 3). The graft survival between the two centers was similar during the follow up period. The 1, 3, and 5 year graft survival was $93 \%, 79 \%$, and $59 \%$ in the CST analytic group and 94\%, 84\%, and 72\% in the RSW analytic group (Figure 1). Death-censored graft survival showed similar results with 1, 3, and 5 year survival at 99\%, 87\%, and 74\% in the CST analytic group and $97 \%, 92 \%$, and $83 \%$ in the RSW analytic group. Patient survival was $94 \%, 91 \%$, and $79 \%$ at 1, 3, and 5 years for the CST analytic group and 97\%, 92\%, and $87 \%$ in the RSW analytic group. The Cox proportional hazard models for graft and patient survival did not show any significant difference in survival between the two analytic groups (Table 4).

\subsection{Causes of Graft Failure and Death}

The causes of graft failure and patient death with a functioning graft are shown in Table 3. Overall, the causes 
Table 2. Patient demographics between continued steroid therapy (CST) and rapid steroid withdrawal (RSW) centers.

\begin{tabular}{|c|c|c|c|c|c|c|}
\hline & \multicolumn{3}{|c|}{ Unmatched Cohort } & \multicolumn{3}{|c|}{ Matched Cohort } \\
\hline & $\begin{array}{c}\text { CST } \\
(\mathrm{n}=194)\end{array}$ & $\begin{array}{c}\text { RSW } \\
(\mathrm{n}=212)\end{array}$ & Cohen’s D & $\begin{array}{c}\text { CST } \\
\left(\mathrm{n}=150^{\mathrm{a}}\right)\end{array}$ & $\begin{array}{c}\text { RSW } \\
(\mathrm{n}=157)\end{array}$ & Cohen's D \\
\hline Age at Transplant (Years) & $49.5(13.4)$ & $51.0(12.6)$ & 0.12 & $51.7(15.2)$ & $51.4(13.1)$ & -0.02 \\
\hline Male Recipient & $58 \%$ & $65 \%$ & 0.14 & $60 \%$ & $62 \%$ & 0.04 \\
\hline Body Mass Index (kg/m²) & $29.4(6.3)$ & $30.5(7.1)$ & 0.16 & $29.7(7.1)$ & $30.2(7.1)$ & 0.07 \\
\hline Deceased Donor & $89 \%$ & $49 \%$ & -0.81 & $69 \%$ & $62 \%$ & -0.14 \\
\hline Extended Criteria Donor & $15 \%$ & $15 \%$ & -0.01 & $18 \%$ & $17 \%$ & -0.03 \\
\hline Donation after Cardiac Death & $25 \%$ & $5 \%$ & -0.90 & $7 \%$ & $7 \%$ & 0.00 \\
\hline Diabetes & $31 \%$ & $41 \%$ & 0.20 & $32 \%$ & $39 \%$ & 0.13 \\
\hline \multicolumn{7}{|l|}{ Cause of ESRD } \\
\hline Diabetes & $25 \%$ & $31 \%$ & 0.13 & $26 \%$ & $30 \%$ & 0.09 \\
\hline Hypertension & $51 \%$ & $50 \%$ & -0.02 & $50 \%$ & $50 \%$ & 0.01 \\
\hline FSGS & $9 \%$ & $6 \%$ & -0.13 & $5 \%$ & $6 \%$ & 0.05 \\
\hline Other & $15 \%$ & $14 \%$ & -0.05 & $19 \%$ & $13 \%$ & -0.16 \\
\hline Hepatitis C & $4 \%$ & $12 \%$ & 0.26 & $8 \%$ & $8 \%$ & 0.02 \\
\hline Dialysis Pre-Transplant & $96 \%$ & $85 \%$ & -0.32 & $93 \%$ & $94 \%$ & 0.04 \\
\hline Time on Dialysis (Years) & $4.7(3.2)$ & $3.4(3.4)$ & -0.38 & $4.2(3.2)$ & $3.9(3.3)$ & -0.08 \\
\hline Donor Age (Years) & $41.2(15.4)$ & $38.3(14.9)$ & -0.19 & $39.5(15.8)$ & $39.6(15.6)$ & 0.01 \\
\hline Black Donor & $26 \%$ & $60 \%$ & 0.70 & $47 \%$ & $54 \%$ & 0.14 \\
\hline Male Donor & $62 \%$ & $53 \%$ & -0.18 & $55 \%$ & $59 \%$ & 0.07 \\
\hline Donor BMI & $28.3(7.1)$ & $28.9(6.5)$ & 0.09 & $28.0(7.2)$ & $28.1(6.4)$ & 0.02 \\
\hline \multicolumn{7}{|l|}{ HLA Matches } \\
\hline $0-2$ & $64 \%$ & $53 \%$ & -0.21 & $56 \%$ & $56 \%$ & 0.00 \\
\hline $3-4$ & $28 \%$ & $37 \%$ & 0.17 & $35 \%$ & $36 \%$ & 0.02 \\
\hline $5-6$ & $8 \%$ & $10 \%$ & 0.07 & $9 \%$ & $8 \%$ & -0.03 \\
\hline PRA $>30 \%$ & $22 \%$ & $8 \%$ & -0.55 & $11 \%$ & $10 \%$ & -0.06 \\
\hline \multicolumn{7}{|l|}{ CMV Risk } \\
\hline Low & $11 \%$ & $6 \%$ & -0.22 & $9 \%$ & $8 \%$ & -0.04 \\
\hline Intermediate & $79 \%$ & $84 \%$ & 0.14 & $83 \%$ & $84 \%$ & 0.03 \\
\hline High & $10 \%$ & $10 \%$ & 0.00 & $8 \%$ & $8 \%$ & -0.01 \\
\hline \multicolumn{7}{|l|}{ Transplant Era } \\
\hline 2003-2005 & $26 \%$ & $25 \%$ & -0.04 & $27 \%$ & $25 \%$ & -0.05 \\
\hline 2006-2008 & $37 \%$ & $30 \%$ & -0.16 & $27 \%$ & $32 \%$ & 0.11 \\
\hline 2009-2012 & $37 \%$ & $46 \%$ & 0.18 & $46 \%$ & $43 \%$ & -0.06 \\
\hline
\end{tabular}

Reported as either mean (standard deviation) or proportions. ${ }^{a}$ Weighted total, rounded to the nearest whole number.

of graft failure were similar between the two groups with interstitial fibrosis/tubular atrophy being the most common followed by acute rejection. The causes of death were difficult to determine for a number of cases, particularly in the RSW group. However, it appeared that the most common causes were either cardiovascular, infectious, or due to malignancy. 
Table 3. Graft failure and deaths between the continued steroid therapy (CST) and rapid steroid withdrawal (RSW) group.

\begin{tabular}{|c|c|c|c|c|c|}
\hline & \multicolumn{2}{|c|}{$\operatorname{CST}\left(\mathrm{n}=150^{\mathrm{a}}\right)$} & \multicolumn{2}{|c|}{ RSW (n = 157) } & \multirow[b]{2}{*}{ p-Value } \\
\hline & $\mathrm{n}^{\mathrm{a}}$ & Incidence $(95 \% \mathrm{CI})$ & $\mathrm{n}$ & Incidence (95\% CI) & \\
\hline Graft Failure & 25 & $17 \%(9 \%-28 \%)$ & 24 & $15 \%(10 \%-22 \%)$ & 0.82 \\
\hline Cause of Graft Failure & & & & & 0.64 \\
\hline Acute Rejection & 3 & $14 \%(3 \%-42 \%)$ & 7 & $29 \%(14 \%-51 \%)$ & \\
\hline Primary & 3 & $14 \%(3 \%-42 \%)$ & 1 & $4 \%(0 \%-26 \%)$ & \\
\hline Infectious & 0 & $0 \%$ & 1 & $4 \%(0 \%-26 \%)$ & \\
\hline Recurrence & 5 & $21 \%(4 \%-60 \%)$ & 2 & $8 \%(2 \%-29 \%)$ & \\
\hline $\begin{array}{l}\text { Interstitial Fibrosis/Tubular } \\
\text { Atrophy }\end{array}$ & 9 & $37 \%(14 \%-68 \%)$ & 8 & $33 \%(17 \%-55 \%)$ & \\
\hline BK Nephropathy & 3 & $13 \%(2 \%-51 \%)$ & 4 & $17 \%(6 \%-38 \%)$ & \\
\hline Other & 0 & $1 \%(0 \%-11 \%)$ & 1 & $4 \%(0 \%-26 \%)$ & \\
\hline Deaths with a Functioning Graft & 24 & $16 \%(8 \%-27 \%)$ & 18 & $11 \%(7 \%-18 \%)$ & 0.40 \\
\hline Cause of Death & & & & & 0.51 \\
\hline Cardiovascular & 8 & $34 \%(10 \%-70 \%)$ & 3 & $17 \%(5 \%-42 \%)$ & \\
\hline Infectious & 4 & $18 \%(5 \%-50 \%)$ & 2 & $11 \%(3 \%-37 \%)$ & \\
\hline Malignancy & 5 & $22 \%(4 \%-66 \%)$ & 2 & $11 \%(3 \%-37 \%)$ & \\
\hline Cerebrovascular & 0 & $3 \%(0 \%-19 \%)$ & 1 & $6 \%(0 \%-33 \%)$ & \\
\hline Unknown & 5 & $20 \%(5 \%-53 \%)$ & 9 & $50 \%(28 \%-72 \%)$ & \\
\hline Other & 1 & $3 \%(0 \%-21 \%)$ & 1 & $6 \%(0 \%-33 \%)$ & \\
\hline
\end{tabular}

a weighted total, rounded to the nearest whole number.

Table 4. Graft outcomes between the continued steroid therapy (CST, reference) group and the rapid steroid withdrawal group.

\begin{tabular}{|c|c|c|c|}
\hline & Unadjusted $^{\mathrm{a}}$ & Model $1^{\mathrm{b}}$ & Model $2^{\mathrm{c}}$ \\
\hline Graft Survival & $0.79(0.48-1.31)$ & $0.81(0.47-1.38)$ & $0.71(0.38-1.34)$ \\
\hline Death-Censored Graft Survival & $0.88(0.44-1.77)$ & $0.95(0.49-1.85)$ & $0.91(0.43-1.91)$ \\
\hline Patient Survival & $0.69(0.32-1.51)$ & $0.62(0.24-1.65)$ & $0.57(0.20-1.67)$ \\
\hline
\end{tabular}

${ }^{\mathrm{a}}$ Unadjusted model with Inverse Probability Treatment Weight (IPTW) adjustment only; ${ }^{\mathrm{b}}$ model 1 includes IPTW plus recipient age, gender, BMI, diabetes, pre-transplant dialysis, dialysis time, cause of ESRD (hypertension, lupus, or other vs diabetes), PRA > 30\%, and Hepatitis C status; ' $m$ model 2 includes model 1 plus donor type (cadaver vs living), expanded criteria donor, donation after circulatory death, HLA matches, donor age, donor gender, donor race (black vs other), donor BMI, CMV risk (intermediate, high vs low), and transplant era (2006-2008, 2009-2012 vs 2003-2005).

\subsection{Renal Function}

The eGFR at 1 and 5 years after transplant are shown in Table 5. Overall, the eGFR were not statistically different between the two groups at 1 and 5 years after transplant. However, when we stratified subjects into type of kidney transplant, recipients of deceased donor kidneys in the CST analytic group had a higher eGFR compared to deceased donors in the RSW analytic group at 1 year $\left(64.1 \mathrm{vs} 52.7 \mathrm{~mL} / \mathrm{min} / 1.73 \mathrm{~m}^{2}, \mathrm{p}=0.047\right)$ that was no longer significant in those that survived out to 5 years (CST 55.3 vs RSW $51.3 \mathrm{~mL} / \mathrm{min} / 1.73 \mathrm{~m}{ }^{2}$, p = 0.59). Living donor kidney transplants were not different at either 1 or 5 years after transplant.

\subsection{Acute Rejection}

The incidence of rejection and types of rejection are shown in Table 5. Compared to the CST analytic group, the RSW analytic group had a higher rate of rejection at 1 (32\% vs 10\%, p < 0.001) and 5 years $(44 \%$ vs $15 \%$, p < 0.001) compared to the CST analytic group. When limited to biopsy-proven rejections in the first year, the rates 


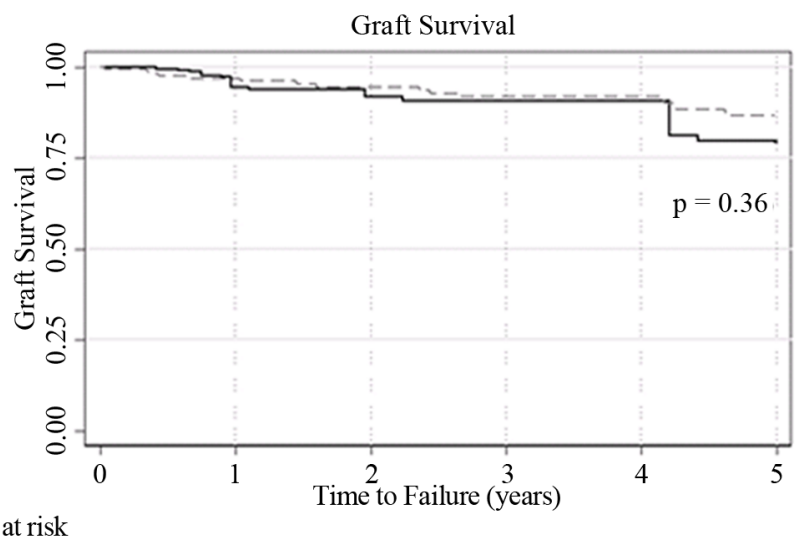

Number at risk

$\begin{array}{llllll}\text { CST } 150 & 137 & 112 & 74 & 46 & 31 \\ \text { RSW } 157 & 130 & 104 & 80 & 56 & 43\end{array}$

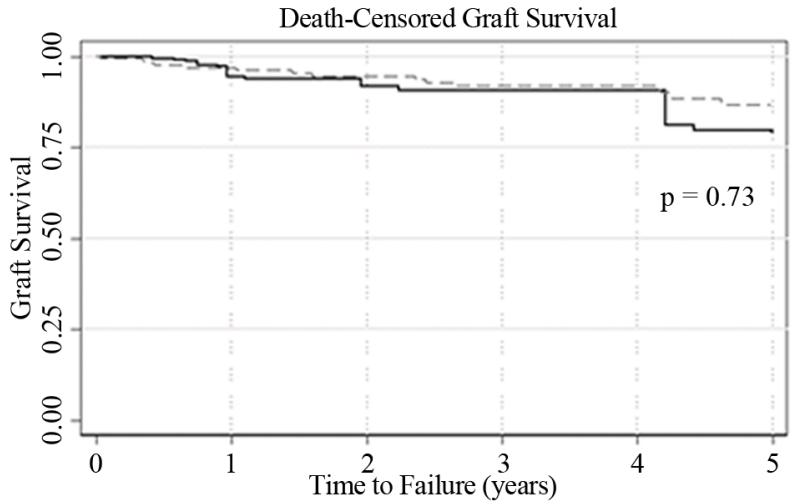

Number at risk

RST 150
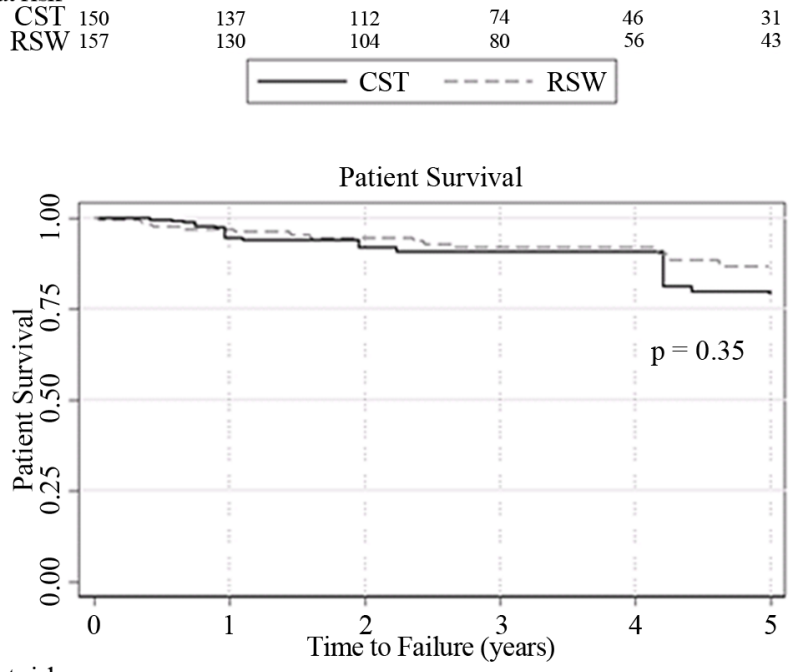

Number at risk

CST 150

RSW 157

$\begin{array}{rccr}137 & 112 & 74 & 46 \\ 130 & 104 & 80 & 56 \\ & \end{array}$

Figure 1. Graft and patient survival all transplants. Kaplan-Meier survival curves adjusted for baseline differences using inverse probability of treatment weights. CST-continued steroid therapy group, RSWrapid steroid withdrawal group. Log-rank p-value is reported for each analysis. 
Table 5. Post-transplant complications between the Continued Steroid Therapy (CST) and Rapid Steroid Withdrawal (RSW) Groups.

\begin{tabular}{|c|c|c|c|c|c|c|c|}
\hline & & $\operatorname{CST}\left(\mathrm{n}=150^{\mathrm{a}}\right)$ & & RSW (n = 157) & & & \\
\hline & $\mathrm{n}^{\mathrm{a}}$ & Weighted Mean (95\% CI) & $\mathrm{n}$ & Weighted Mean (95\% CI) & p-Value & OR (95\% CI) & p-Value \\
\hline $\begin{array}{l}\text { GFR at } 1 \text { Year } \\
\left(\mathrm{mL} / \mathrm{min} / 1.73 \mathrm{~m}^{2}\right)\end{array}$ & 140 & $60.0(51.7-68.3)$ & $\begin{array}{c}13 \\
2\end{array}$ & $52.9(50.1-55.8)$ & 0.11 & & \\
\hline Living Donor & 47 & $51.9(41.1-62.7)$ & 52 & $53.4(49.4-57.3)$ & 0.80 & & \\
\hline Deceased Donor & 93 & $64.1(53.5-74.7)$ & 80 & $52.7(48.7$ - 56.6) & 0.047 & & \\
\hline $\begin{array}{l}\text { GFR at } 5 \text { Years } \\
\left(\mathrm{mL} / \mathrm{min} / 1.73 \mathrm{~m}^{2}\right)\end{array}$ & 49 & $50.7(40.9-60.6)$ & 46 & $52.2(45.6-58.8)$ & 0.80 & & \\
\hline Living Donor & 18 & $42.9(27.7-58.2)$ & 21 & $53.4(45.4-61.3)$ & 0.23 & & \\
\hline \multirow[t]{2}{*}{ Deceased Donor } & 31 & $55.3(44.1-66.5)$ & 25 & $51.3(41.1-61.4)$ & 0.59 & & \\
\hline & $n^{\mathrm{a}}$ & Weighted\% (95\% CI) & $\mathrm{n}$ & Weighted\% (95\% CI) & p-Value & & \\
\hline $\begin{array}{l}\text { Delayed Graft } \\
\text { Function }\end{array}$ & 48 & $32 \%(23 \%-43 \%)$ & 16 & $10 \%(6 \%-16 \%)$ & $<0.001$ & $0.15(0.06-0.35)$ & $<0.001$ \\
\hline $\begin{array}{l}\text { Post-Transplant } \\
\text { Diabetes Mellitus }\end{array}$ & 28 & $25 \%(14 \%-41 \%)$ & 22 & $22 \%(15 \%-31 \%)$ & 0.66 & $0.85(0.32-2.24)$ & 0.74 \\
\hline BK Viremia & 16 & $10 \%(5 \%-20 \%)$ & 28 & $18 \%(13 \%-25 \%)$ & 0.15 & $2.72(1.22-6.04)$ & 0.014 \\
\hline CMV Viremia & 17 & $11 \%(5 \%-21 \%)$ & 37 & $24 \%(18 \%-31 \%)$ & 0.04 & $4.14(1.81-9.44)$ & 0.001 \\
\hline Rejection at 1 Year & 15 & $10 \%(5 \%-18 \%)$ & 51 & $32 \%(26 \%-40 \%)$ & $<0.001$ & $4.26(1.99-9.13)$ & $<0.001$ \\
\hline Rejection at 5 Year & 23 & $15 \%(9 \%-25 \%)$ & 69 & $44 \%(36 \%-52 \%)$ & $<0.001$ & $4.71(2.40-9.23)$ & $<0.001$ \\
\hline $\begin{array}{l}\text { Biopsy Proven } \\
\text { Rejection at } 1 \text { Year }\end{array}$ & 15 & $10 \%(5 \%-18 \%)$ & 28 & $18 \%(13 \%-25 \%)$ & 0.10 & $2.04(0.92-4.55)$ & 0.08 \\
\hline $\begin{array}{l}\text { Biopsy Proven } \\
\text { Rejection at } 5 \text { Year }\end{array}$ & 23 & $15 \%(9 \%-25 \%)$ & 37 & $24 \%(18 \%-31 \%)$ & 0.13 & $1.95(0.98-3.88)$ & 0.06 \\
\hline $\begin{array}{l}\text { Types of Rejection } \\
\text { (Biopsy-Proven) }\end{array}$ & & & & & $<0.001$ & & \\
\hline Grade 1 & 5 & $22 \%(7 \%-50 \%)$ & 28 & $70 \%(54 \%-82 \%)$ & & & \\
\hline Grade 2 & 15 & $68 \%$ (42\% - 87\%) & 2 & $5 \%(1 \%-18 \%)$ & & & \\
\hline Grade 3 & 0 & $0 \%(0 \%-3 \%)$ & 0 & $0 \%$ & & & \\
\hline $\begin{array}{l}\text { Antibody-Mediated } \\
\text { Rejection }\end{array}$ & 2 & $9 \%(3 \%-24 \%)$ & 5 & $12 \%(5 \%-27 \%)$ & & & \\
\hline $\begin{array}{l}\text { Borderline } \\
\text { Rejection }\end{array}$ & 0 & $0 \%(0 \%-2 \%)$ & 5 & $12 \%(5 \%-27 \%)$ & & & \\
\hline
\end{tabular}

a weighted total, rounded to the nearest whole number.

were similar (18\% vs 10\%, p = 0.10). The types of biopsy-proven rejection varied by group with more grade 1 and borderline rejections in the RSW analytic group while grade 2 rejections were more common in the CST analytic group.

\subsection{Other Complications}

The incidence of delayed graft function was much higher among the CST analytic group compared to the RSW analytic group (32\% vs 10\%, p < 0.001) (Table 5). The incidence of post-transplant diabetes mellitus was similar between the two groups $(25 \%$ vs $22 \%, \mathrm{p}=0.66)$. In regards to viral infections, CMV viremia was more commonly found in the RSW analytic group compared to the CST analytic group (24\% vs $11 \%, \mathrm{p}=0.036$ ) while BK viremia was similar between two groups (18\% vs $10 \%, \mathrm{p}=0.15)$.

\subsection{Return to Corticosteroid Therapy}

Among the RSW group, 20 of the 157 individuals were started on prednisone after their transplant (Table 6). 
Table 6. Prednisone initiation in the rapid steroid withdrawal group.

\begin{tabular}{ccc}
\hline & $\mathrm{n}$ & Percentage of RSW $(\mathrm{n}=157)$ \\
\hline $\begin{array}{c}\text { Started on Prednisone } \\
\text { Reasons for Starting Prednisone }\end{array}$ & 20 & $6.5 \%$ \\
Rejection & 7 & $35 \%$ \\
Leukopenia & 5 & $25 \%$ \\
BK Nephropathy & 2 & $10 \%$ \\
GI Intolerance & 2 & $10 \%$ \\
Malignancy & 1 & $5 \%$ \\
FSGS & 1 & $5 \%$ \\
Pregnancy & 1 & $5 \%$ \\
FK Toxicity & 1 & $5 \%$ \\
\hline
\end{tabular}

The most common cause of starting prednisone was rejection (35\%). The next most common cause was leukopenia at $25 \%$ while BK nephropathy and GI intolerance to mycophenolate mofetil or mycophenolate sodium were each $10 \%$. Of the 20 individuals, 13 (65\%) were started in the first year of transplant.

\section{Discussion}

The use of RSW has become more common practice in the management of renal allografts to prevent the side effects of prolonged corticosteroid use. Of patients transplanted in 2011, nearly $40 \%$ of recipients were discharged off steroid maintenance with nearly 30\% remaining steroid-free at 1 year post-discharge [28] [29]. This study represents the first comparative study of RSW versus CST in AA recipients. A similar number of recipients were included from both centers within similar age ranges. However, there were notable differences in the types of transplants performed at each center. The CST group included more patients with deceased donor kidneys, donor after circulatory death kidneys, increased HLA mismatches and a higher proportion of PRA > 30\% recipients as well as recipients receiving renal replacement therapy at the time of transplant when compared to the RSW group. To reduce these biases, we used propensity score weighting with inverse probability of treatment weights to adjust for these differences and then incorporated covariates into a regression model for a doubly robust estimation.

There were few statistically significant differences in allograft function or rejection outcomes within the first year of transplantation (Table 5). Allograft function appeared superior within the CST group at 1 year but the difference was marginal in those that survived out to 5 years. Graft, death-censored graft survival, and patient survival did not appear to be significantly affected by the use of maintenance steroids. The RSW group had a higher rate of CMV viremia while the CST group had a higher rate of delayed graft function. The combined empiric and biopsy-proven acute rejection rate was higher in the RSW group although the incidence of biopsy-proven acute rejection was similar between the two cohorts. Among the biopsy-proven acute rejections, borderline or grade 1 rejections were more likely to be seen in the RSW group while the CST group had more grade 2 rejections, similar to what has been previously reported in other comparison studies.

The practice of using an RSW protocol has improved corticosteroid related complications in renal transplant recipients [8] [9] [21] [30]-[33]. Surprisingly, the incidence of PTDM development remained equal between centers. One would have expected increased post-transplant diabetes in the CSW group but this was not seen in our retrospective analysis. This may be explained, in part, by the higher percentage of patients with Hepatitis C and higher BMI in the RSW group, two established risk factors in the development of PTDM [34]. Further, when compared to the larger steroid doses of the past, a daily dose of $5 \mathrm{mg}$ of prednisone may not significantly contribute to the development of insulin resistance post-transplant [35]. Glycemic control was not assessed in this study but others have shown worse control in those maintained on steroids compared to early withdrawal [32] [33] [36].

Few studies have specifically addressed the clinical outcomes in AA kidney transplant recipients with regards 
to RSW [17]-[23]. A small, single-center study comparing 56 AA vs. 56 non-AA recipients on varying immunosuppression regimens showed acceptable rejection rates and patient-/graft-survival when prospectively followed up to 3 years [22]. Additionally, long-term outcomes have been published when comparing protocol biopsies between AA and non-AA recipients on RSW protocols [19] [20]. Both studies indicated favorable graft and patient survival outcomes in low PRA AA recipients when compared to non-AA recipients. More recently, a study of 634 recipients of which $27 \%$ of patients were AA, showed AA race to be associated with increased rejection and graft loss. Unlike previous studies, 55\% of total recipients received deceased donor kidneys of which $46 \%$ of the $55 \%$ transplanted were from expanded criteria donors [17]. The risk of recurrent disease was similar between the two groups but this subgroup was small. In a few reported studies, the risk of recurrence of glomerulonephritis was similar between steroid maintenance and steroid withdrawal groups [37] [38] except in IgA nephropathy where the risk of recurrence was higher in steroid withdrawal groups [39] [40].

While this study includes one of the largest cohorts of African-Americans, the study does have some limitations. First, the study was conducted as a retrospective chart review at two centers where differences in practice may have affected the results. The major difference is type of kidney donors used between the groups, specifically the higher percentage of deceased donors in the CST group compared to the percentage of living donors within the RSW group. To minimize these differences, we used propensity score weighting to match individuals between the two groups and removed matched samples where a few individuals in the control group represent a disproportionately high number in the treatment group. We then adjusted for the covariates along with propensity score weighting to give a doubly robust estimation to further minimize the biases. Other variations include CMV management post-transplant and goal trough levels of tacrolimus being different between groups. Interestingly, CMV viremia was seen more in the RSW with the longer valganciclovir prophylaxis. And while we were unable to gather the data on trough levels in either group, the lower target levels of tacrolimus in the CST group may explain why eGFR was higher then in this group. Finally, the high number of empirically treated rejections in the RSW group likely underestimates the biopsy-proven rejection rate since other studies of steroid withdrawal have shown higher rejection rates. Despite these significant differences in practice between these two centers where these differences could bias the outcomes in favor of the CST protocol, we still found no difference in graft and patient survival. However, more prospective, long-term, controlled studies are needed to confirm these findings before recommending the routine use of RSW protocols in African-American kidney transplant recipients.

\section{Conclusion}

We conclude that a RSW regimen is comparable in graft and patient survival to a CST regimen in AA recipients.

\section{Acknowledgements}

The authors declare no conflicts of interest. Sanjeev Akkina's effort was supported by the National Institute of Health, National Institute of Diabetes and Digestive and Kidney Diseases grant DK084121. The results presented in this paper have not been published previously in whole or part, except in abstract form.

\section{References}

[1] Luan, F.L., Steffick, D.E., Gadegbeku, C., Norman, S.P., Wolfe, R. and Ojo, A.O. (2009) Graft and Patient Survival in Kidney Transplant Recipients Selected for de Novo Steroid-Free Maintenance Immunosuppression. American Journal of Transplantation, 9, 160-168. http://dx.doi.org/10.1111/j.1600-6143.2008.02442.x

[2] Matas, A.J., et al. (2005) Prednisone-Free Maintenance Immunosuppression-A 5-Year Experience. American Journal of Transplantation, 5, 2473-2478. http://dx.doi.org/10.1111/j.1600-6143.2005.01051.X

[3] Zhang, X., Huang, H.J., Han, S., Fu, S.X. and Wang, L.M. (2013) Is It Safe to Withdraw Steroids within Seven Days of Renal Transplantation? Clinical Transplantation, 27, 1-8. http://dx.doi.org/10.1111/ctr.12015

[4] Iwamoto, H., Hama, K., Konno, O., Yokoyama, T., Kihara, Y., Jojima, Y., Nakamura, Y., Takeuchi, H. and Shimazu, M. (2012) Early Steroid Withdrawal in Adult Kidney Transplantation at a Single Center. Transplantation Proceedings, 44, 179-181. http://dx.doi.org/10.1016/j.transproceed.2011.12.068

[5] Knight, S.R. and Morris, P.J. (2011) Interaction between Maintenance Steroid Dose and the Risk/Benefit of Steroid Avoidance and Withdrawal Regimens Following Renal Transplantation. Transplantation, 92, e63-e64. 
http://dx.doi.org/10.1097/TP.0b013e3182370611

[6] Pascual, J. (2011) Steroid Avoidance or Withdrawal in Kidney Transplantation. Current Opinion in Organ Transplantation, 16, 600-605. http://dx.doi.org/10.1097/MOT.0b013e32834c23fa

[7] Pascual, J., et al. (2012) Very Early Steroid Withdrawal or Complete Avoidance for Kidney Transplant Recipients: A Systematic Review. Nephrology Dialysis Transplantation, 27, 825-832. http://dx.doi.org/10.1093/ndt/gfr374

[8] Pascual, J., Galeano, C., Quereda, C., Royuela, A. and Zamora, J. (2009) Steroid Avoidance or Withdrawal for Kidney Transplant Recipients. Cochrane Database of Systematic Reviews, CD005632. http://dx.doi.org/10.1002/14651858.cd007669

[9] Woodle, E.S., et al. (2008) A Prospective, Randomized, Double-Blind, Placebo-Controlled Multicenter Trial Comparing Early (7 day) Corticosteroid Cessation versus Long-Term, Low-Dose Corticosteroid Therapy. Annals of Surgery, 248, 564-577. http://dx.doi.org/10.1097/sla.0b013e318187d1da

[10] Vincenti, F., et al. (2008) A Randomized, Multicenter Study of Steroid Avoidance, Early Steroid Withdrawal or Standard Steroid Therapy in Kidney Transplant Recipients. American Journal of Transplantation, 8, 307-316. http://dx.doi.org/10.1111/j.1600-6143.2007.02057.x

[11] Rajab, A., Pelletier, R.P., Henry, M.L. and Ferguson, R.M. (2006) Excellent Clinical Outcomes in Primary Kidney Transplant Recipients Treated with Steroid-Free Maintenance Immunosuppression. Clinical Transplantation, 20, 537546. http://dx.doi.org/10.1111/j.1399-0012.2006.00521.x

[12] Kumar, M.S., et al. (2006) Safety and Efficacy of Steroid Withdrawal Two Days after Kidney Transplantation: Analysis of Results at Three Years. Transplantation, 81, 832-839. http://dx.doi.org/10.1097/01.tp.0000203558.34739.c6

[13] Teraoka, S., et al. (2005) Comparative Study of Clinical Outcome in Kidney Transplantation between Early Steroid Withdrawal Protocol Using Basiliximab, Calcineurin Inhibitor, and Mycophenolate Mofetil and Triple Regimen Consisting of Calcineurin Inhibitor, Mycophenolate Mofetil, and Steroid. Transplantation Proceedings, 37, 791-794. http://dx.doi.org/10.1016/j.transproceed.2004.12.185

[14] Laftavi, M.R., et al. (2005) Randomized Prospective Trial of Early Steroid Withdrawal Compared with Low-Dose Steroids in Renal Transplant Recipients Using Serial Protocol Biopsies to Assess Efficacy and Safety. Surgery, 137, 364-371. http://dx.doi.org/10.1016/j.surg.2004.10.013

[15] Woodle, E.S., et al. (2005) A Multicenter Pilot Study of Early (4-Day) Steroid Cessation in Renal Transplant Recipients under Simulect, Tacrolimus and Sirolimus. American Journal of Transplantation, 5, 157-166. http://dx.doi.org/10.1111/j.1600-6143.2004.00655.x

[16] Khwaja, K., et al. (2004) Outcome at 3 Years with a Prednisone-Free Maintenance Regimen: A Single-Center Experience with 349 Kidney Transplant Recipients. American Journal of Transplantation, 4, 980-987. http://dx.doi.org/10.1111/j.1600-6143.2004.00443.x

[17] Aull, M.J., et al. (2012) Early Corticosteroid Withdrawal in Recipients of Renal Allografts: A Single-Center Report of Ethnically Diverse Recipients and Recipients of Marginal Deceased-Donor Kidneys. Transplantation, 94, 837-844. http://dx.doi.org/10.1097/TP.0b013e318265c461

[18] Padiyar, A., Augustine, J.J., Bodziak, K.A., Aeder, M., Schulak, J.A. and Hricik, D.F. (2010) Influence of AfricanAmerican Ethnicity on Acute Rejection after Early Steroid Withdrawal in Primary Kidney Transplant Recipients. Transplantation Proceedings, 42, 1643-1647. http://dx.doi.org/10.1016/j.transproceed.2010.02.081

[19] Anil Kumar, M.S., Khan, S., Ranganna, K., Malat, G., Sustento-Reodica, N. and Meyers, W.C. (2008) Long-Term Outcome of Early Steroid Withdrawal after Kidney Transplantation in African American Recipients Monitored by Surveillance Biopsy. American Journal of Transplantation, 8, 574-585. http://dx.doi.org/10.1111/j.1600-6143.2007.02099.x

[20] Zeng, X., et al. (2007) Intermediate-Term Outcomes with Early Steroid Withdrawal in African-American Renal Transplant Recipients Undergoing Surveillance Biopsy. Surgery, 142, 538-544; Discussion 544-545. http://dx.doi.org/10.1016/j.surg.2007.07.006

[21] Haririan, A., Sillix, D.H., Morawski, K., El-Amm, J.M., Garnick, J., Doshi, M.D., West, M.S. and Gruber, S.A. (2006) Short-Term Experience with Early Steroid Withdrawal in African-American Renal Transplant Recipients. American Journal of Transplantation, 6, 2396-2402. http://dx.doi.org/10.1111/j.1600-6143.2006.01477.x

[22] Boardman, R.E., et al. (2005) African American Renal Transplant Recipients Benefit from Early Corticosteroid Withdrawal under Modern Immunosuppression. Transplantation Proceedings, 37, 814-816. http://dx.doi.org/10.1016/j.transproceed.2004.12.071

[23] Schold, J.D., Srinivas, T.R., Braun, W.E., Shoskes, D.A., Nurko, S. and Poggio, E.D. (2011) The Relative Risk of Overall Graft Loss and Acute Rejection Among African American Renal Transplant Recipients Is Attenuated with Advancing Age. Clinical Transplantation, 25, 721-730. http://dx.doi.org/10.1111/j.1399-0012.2010.01343.x

[24] Khwaja, K., et al. (2004) Rapid Discontinuation of Prednisone in Higher-Risk Kidney Transplant Recipients. Trans- 
plantation, 78, 1397-1399. http://dx.doi.org/10.1097/01.TP.0000136964.59494.FF

[25] Bang, H. and Robins, J.M. (2005) Doubly Robust Estimation in Missing Data and Causal Inference Models. Biometrics, 61, 962-973. http://dx.doi.org/10.1111/j.1541-0420.2005.00377.x

[26] Stuart, E.A. and Rubin, D.B. (2007) Best Practices in Quasi-Experimental Designs: Matching Methods for Causal Inference. In: Osborne, J, Ed., Best Practices in Quantitative Methods, Thousand Oaks, Sage Publications, 155-176.

[27] Ho, D.E., Imai, K., King, G. and Stuart, E.A. (2007) Matching as Nonparametric Preprocessing for Reducing Model Dependence in Parametric Causal Inference. Political Analysis, 15, 199-236. http://dx.doi.org/10.1093/pan/mpl013

[28] (SRTR) O.P.a.T.N.O.a.S.R.o.T.R. OPTN/SRTR 2011 Annual Data Report-Immunosuppression Use for Maintenance Between Discharge and One Year Following Transplantation, 2001-2010—Recipients with Kidney Transplants. Table 5.6 g. Department of Health and Human Services, Health Resources and Services Administration, Healthcare Systems Bureau, Division of Transplantation, 2012. http://www.srtr.org/annual_Reports/2011/506d_ki.aspx

[29] (SRTR) O.P.a.T.N.O.a.S.R.o.T.R. OPTN/SRTR 2011 Annual Data Report-Immunosuppression Use for Maintenance by Regimen Prior to Discharge, 2002 to 2011—Recipients with Kidney Transplants. Table 5.6 d. Department of Health and Human Services, Health Resources and Services Administration, Healthcare Systems Bureau, Division of Transplantation, 2012. http://www.srtr.org/annual_Reports/2011/506g_ki.aspx

[30] Knight, S.R. and Morris, P.J. (2010) Steroid Avoidance or Withdrawal after Renal Transplantation Increases the Risk of Acute Rejection But Decreases Cardiovascular Risk. A Meta-Analysis. Transplantation, 89, 1-14. http://dx.doi.org/10.1097/TP.0b013e3181c518cc

[31] Opelz, G. and Dohler, B. (2013) Association between Steroid Dosage and Death with a Functioning Graft after Kidney Transplantation. American Journal of Transplantation, 13, 2096-2105. http://dx.doi.org/10.1111/ajt.12313

[32] Gonzalez-Molina, M., et al. (2010 Effect of Long-Term Steroid Withdrawal in Renal Transplant Recipients: A Retrospective Cohort Study. NDT Plus, 3, ii32-ii36.

[33] Rike, A.H., et al. (2008) Cardiovascular Risk, Cardiovascular Events, and Metabolic Syndrome in Renal Transplantation: Comparison of Early Steroid Withdrawal and Chronic Steroids. Clinical Transplantation, 22, 229-235. http://dx.doi.org/10.1111/j.1399-0012.2007.00779.x

[34] Kasiske, B.L., et al. (2003) Diabetes Mellitus after Kidney Transplantation in the United States. American Journal of Transplantation, 3, 178-185. http://dx.doi.org/10.1034/j.1600-6143.2003.00010.x

[35] Midtvedt, K., et al. (2004) Insulin Resistance after Renal Transplantation: The Effect of Steroid Dose Reduction and Withdrawal. Journal of the American Society of Nephrology, 15, 3233-3239. http://dx.doi.org/10.1097/01.asn.0000145435.80005.1e

[36] Pirsch, J.D., Henning, A.K., First, M.R., Fitzsimmons, W., Gaber, A.O., Reisfield, R., Shihab F. and Woodle, E.S. (2015) New-Onset Diabetes after Transplantation: Results From a Double-Blind Early Corticosteroid Withdrawal Trial. American Journal of Transplantation, 15, 1982-1990. http://dx.doi.org/10.1111/ajt.13247

[37] Ibrahim, H., et al. (2006) Graft Loss from Recurrent Glomerulonephritis Is Not Increased with a Rapid Steroid Discontinuation Protocol. Transplantation, 81, 214-219. http://dx.doi.org/10.1097/01.tp.0000188656.44326.53

[38] Boardman, R., et al. (2005) Early Steroid Withdrawal Does Not Increase Risk for Recurrent Focal Segmental Glomerulosclerosis. Transplantation Proceedings, 37, 817-818. http://dx.doi.org/10.1016/j.transproceed.2004.12.065

[39] Clayton, P., McDonald, S. and Chadban, S. (2011) Steroids and Recurrent IgA Nephropathy after Kidney Transplantation. American Journal of Transplantation, 11, 1645-1649. http://dx.doi.org/10.1111/j.1600-6143.2011.03667.x

[40] Von Visger, J.R., et al. (2014) The Risk of Recurrent IgA Nephropathy in a Steroid-Free Protocol and Other Modifying Immunosuppression. Clinical Transplantation, 28, 845-854. http://dx.doi.org/10.1111/ctr.12389 


\section{Abbreviations}

AA: African-American

ACR: Acute cellular rejection

BMI: Body mass index

CMV: Cytomegalovirus

CST: Continued steroid therapy

DCD: Donation after circulatory death

ECD: Expanded criteria donors

IPTW: Inverse probability of treatment weights

PRA: panel reactive antibodies

PTDM: Post-transplant diabetes mellitus

RSW: Rapid steroid withdrawal 